\title{
Role of Endorectal Prostate MRI in Patients with Initial Suspicion of Prostate Cancer
}

\section{Wertigkeit der MRT der Prostata bei Patienten mit initialem Verdacht auf ein Prostatakarzinom}

Authors

Affiliations
T. Franiel ${ }^{1,2}$, H. A. Vargas ${ }^{2}$, Y. Mazaheri², S. Böhmer³ ${ }^{3}$ H. Hricak² ${ }^{2}$ O. Akin², D. Beyersdorff ${ }^{4}$

Department of Radiology, University Hospital Jena

2 Department of Radiology, Memorial Sloan-Kettering Cancer Centre, New York

Urology, ATURO BERLIN, Berlin

Department of Radiology, Charité, University Hospital, Campus Mitte, Berlin
Key words

- prostate cancer

- initial suspicion

- MRI

eingereicht 11.3.2013

akzeptiert 15.7.2013

Bibliography

Dol http://dx.doi.org/

10.1055/s-0033-1350415

Published online: 2.9 .2013

Fortschr Röntgenstr 2013; 185:

967-974 @ Georg Thieme

Verlag KG Stuttgart · New York .

ISSN 1438-9029

\section{Correspondence}

\section{Dr. Tobias Franiel}

Department of Diagnostic and Interventional Radiology, University Hospital Jena Erlanger Alle 101

07747 Jena

Germany

Tel.: ++49/3641/9324831

Fax: ++49/3641/9324832

tobias.franiel@med.uni-jena.de

\section{Zusammenfassung}

$\nabla$

Ziel: Diese retrospektive Studie untersucht die Wertigkeit der MRT der Prostata mit Endorektalspule bei Patienten mit initialem Verdacht auf ein Prostatakarzinom.

Material und Methoden: Ein positives Votum der lokalen Ethikkommission lag vor. 87 Patienten mit initialem Verdacht auf ein Prostatakarzinom wurden im 1,5 Tesla MRT mit der kombinierten Endorektal-Body phased array Spule untersucht. Anschließend erfolgte eine systematische TRUSgestützte 12fach-Biopsie. Jede Prostata wurde entsprechend dem Schema der Stanzbiopsie in 12 Areale unterteilt. Mit den T1w- und T2w-MRT-Aufnahmen wurde für jedes Areal von 3 unabhängigen Radiologen standardisiert und auf einer 5-PunkteSkala die Wahrscheinlichkeit für ein Prostatakarzinom angegeben. Eine ROC-Analyse und eine deskriptive Statistik wurde durchgeführt. Negativ prädiktiver Wert, Sensitivität, Spezifität und positiv-prädiktiver Wert wurden nach Dichotomisierung des Scores (benigne $=$ Score 1 und 2, maligne $=$ Score $3,4,5)$ berechnet .

Ergebnisse: 47/87 Patienten (26 low-grade, 21 high-grade) mit 184/1044 Stanzbiopsien (77 lowgrade, 107 high-grade) waren positiv für ein Prostatakarzinom. Ein Karzinompatient hatte im Median 3 positive Stanzbiopsien (Spannweite 1 - 12). Die Area under ROC curve für die Detektion des Prostatakarzinoms betrug zwischen 0,65-0,67 und bei ausschließlicher Berücksichtigung der high-grade-Prostatakarzinome zwischen 0,750,76. Für die Detektion der Prostatakarzinome/ high-grade-Prostatakarzinome ergab sich ein negativ-prädiktiver Wert von 87,4\%-88,2\%/92,6\%$93,1 \%$, eine Spezifität von $72,3-79,4 \% / 71,5-$ $79,8 \%$, eine Sensitivität 49,5-54,8\%/62,6-69,2\% und ein positiv-prädiktiver Wert von $29,3-34,0 \%$ | $29,4-34,7 \%$.

Schlussfolgerung: Bei Patienten mit initialem Verdacht auf ein Prostatakarzinom kann ein nega-

\section{Abstract \\ $\nabla$}

Purpose: To evaluate the role of conventional endorectal prostate MRI in patients with initial suspicion of prostate cancer.

Materials and Methods: Ethics board approval was received for this retrospective study of 87 men who underwent 1.5-Tesla conventional prostate MRI with a combination of endorectal and body phased-array coils for suspected prostate cancer before their first systematic 12-core TRUS-guided biopsy. Three radiologists independently analyzed the images, dividing the prostate into 12 regions corresponding to the biopsy scheme and scoring each region for the presence of prostate cancer on a 5-point scale. Results were analyzed by prostate region. ROC analysis was done and descriptive statistics were calculated. The negative predictive value, specificity, sensitivity and positive predictive value were calculated using dichotomized scores (benign tissue = scores of 1 and 2; malignant tissues $=$ scores of 3 , 4 , and 5).

Results: Biopsy revealed cancer in $47 / 87$ patients (26 low-grade [Gleason score 6]; 21 high-grade [Gleason score $\geq 3+4]$ ), and $184 / 1044$ cores (77 low-grade and 107 high-grade) with a median of 3 positive cores per cancer patient (range 1 -12). The areas under ROC curves were $0.65-0.67$ for cancer detection by region overall and $0.75-0.76$ for the detection of high-grade cancer by region. Statistic figures for the detection of all cancers/ high-grade cancers by region were as follows: negative predictive value, $87.4-88.2 \% / 92.6-93.1 \%$; specificity, $72.3-79.4 \% / 71.5-79.8 \%$; sensitivity, $49.5-54.8 \% / 62.6-69.2 \%$; and positive predictive value, $29.3-34.0 \% / 29.4-34.7 \%$.

Conclusion: In patients with suspected prostate cancer, negative MRI findings indicate the absence of high-grade prostate cancer on subsequent TRUS-guided 12-core biopsy with high probability. However, agreement between con- 
tives MRT mit sehr hoher Wahrscheinlichkeit das Vorliegen eines high-grade-Prostatakarzinoms in der nachfolgenden TRUS-gestützten Stanzbiopsie ausschließen. Insgesamt stimmen jedoch die Ergebnisse der konventionellen 1,5 Tesla MRT mit Endorektalspule mit den Ergebnissen der systematischen TRUS gestützten Biopsie nur moderat überein. ventional 1.5-T endorectal prostate MRI and systematic 12-core TRUS-guided biopsy for the detection of prostate cancer appears to be moderate.

Citation Format:

- Franiel T, Vargas AH, Mazaheri Y et al. Role of Endorectal Prostate MRI in Patients with Initial Suspicion of Prostate Cancer. Fortschr Röntgenstr 2013; 185: 967-974

\section{Introduction}

$\nabla$

Systematic core biopsy guided by transrectal ultrasound (TRUS) is currently the diagnostic test of choice in men with suspected prostate cancer. However, the initial biopsy detects prostate cancer in only $22 \%$ of cases [1]. Given the large number of negative biopsies, it is understandable that many men choose not to have a biopsy after weighing the benefits and risks [2]. To overcome this dilemma and avoid unnecessary sampling of normal prostate tissue, it would be highly desirable to have a noninvasive diagnostic tool-preferably an imaging modality-that reliably identifies normal prostate tissue without missing cancer. To meet these needs, a diagnostic modality must combine high negative predictive value with high sensitivity.

In patients with histologically proven prostate cancer, conventional endorectal prostate MRI has shown good sensitivities (61-80\%) and good negative predictive values (76-79\%) with areas under receiver operating characteristic curves [AUC] of up to $0.79[3,4]$. High sensitivity $(83 \%)$, high negative predictive value (89\%), and good accuracy (68\%) have also been achieved in patients with a persistent suspicion of prostate cancer following at least one negative TRUS-guided biopsy [5]. Only a few published studies have investigated the value of prostate MRI in men scheduled for their first TRUS-guided prostate biopsy. These studies used the entire prostate or the hemi-prostate as the unit of analysis for comparison with the results of sextant or octant TRUS-guided biopsy, did not consistently use an endorectal coil, or included only the peripheral zone in the analysis [6-9].

In a large population of patients scheduled for their first TRUSguided prostate biopsy, we conducted a study to determine the negative predictive value, sensitivity, specificity, and positive predictive value of conventional prostate MRI performed using the combination of an endorectal coil and a body phased-array coil (conventional endorectal prostate MRI). MRI datasets were retrospectively analyzed independently by three radiologists experienced in prostate cancer imaging, and MRI findings in each patient were correlated to findings from each of the 12 prostatic regions sampled during systematic 12 -core biopsy.

\section{Materials and Methods \\ $\nabla$}

\section{Patients}

This retrospective study was approved by the institutional review board and was compliant with the Health Insurance Portability and Accountability Act. Between July 2003 and February 2008 , a total of 92 consecutive patients in whom prostate cancer was suspected due to elevated PSA, abnormal PSA velocity, or suspicious findings on digital rectal exam underwent conventional endorectal prostate MRI at 1.5 Tesla before having their first systematic TRUS-guided 12-core biopsy. The biopsies were obtained in a standardized manner in all patients. At histopathological evaluation, the Gleason grading system was used, and prostate cancer was classified as low grade (Gleason score of $3+3$ ) or high grade (Gleason score of $3+4$ or above) [10]. Targeted tissue specimens based on suspicious MRI findings were not obtained. 2 of the 92 patients were excluded because their MR images were non-diagnostic due to motion artifacts. Another 3 patients were excluded because the interval between MRI and biopsy was longer than 6 months. Thus, the study included a total of 87 patients.

\section{MRI Protocol}

All patients underwent conventional prostate MRI on a 1.5-Tesla whole-body MR imager (Magnetom Sonata, Siemens, Erlangen, Germany) using the combination of an endorectal coil and a body phased-array coil (conventional endorectal prostate MRI). The body phased-array coil was used for signal transmission, while two elements of a spine-array coil, two elements of a body phased-array coil, and an endorectal coil (Medrad, Pittsburgh, PA) were used for signal reception. Following the acquisition of axial, sagittal, and coronal localizer sequences, the prostate and seminal vesicles were imaged according to a standardized protocol including the following sequences: an axial T2-weighted (w) turbo spin echo (TSE) sequence oriented perpendicular to the longitudinal prostate axis (TR $3720 \mathrm{~ms}$, TE $100 \mathrm{~ms}$, echo train length [ETL] 13, field of view [FOV] $16 \times 16 \mathrm{~cm}$ ), an axial T1w TSE sequence (TR $530 \mathrm{~ms}$, TE $10 \mathrm{~ms}$, ETL 3, FOV $16 \times 16 \mathrm{~cm}$ ) angled in the same way as the T2w sequence, and an angled coronal T2w TSE sequence (TR $3720 \mathrm{~ms}$, TE $100 \mathrm{~ms}$, ETL 13, FOV $16 \times 16 \mathrm{~cm}$ ). All pulse sequences were acquired with a $256 \times 256$ matrix; 3.0 $\mathrm{mm}$ slice thickness, $0.9-\mathrm{mm}$ inter-slice gap, and $100 \%$ phase oversampling. Lymph nodes and the bones were assessed using a proton-density (PD) sequence (TR $1200 \mathrm{~ms}$, TE $13 \mathrm{~ms}$, FOV $32 \times 24 \mathrm{~cm}$, slice thickness $7 \mathrm{~mm}$ ). The patients received an intramuscular injection of $20 \mathrm{mg}$ butylscopolamine (Buscopan; Boehringer Ingelheim, Germany) to suppress artifacts caused by intestinal motion.

\section{Interpretation of MR Images}

The MRI datasets were randomized and retrospectively evaluated for areas of prostate cancer by three radiologists with 2, 4 and 8 years of prostate MRI experience. The readings were recorded independently. The readers were blinded to PSA levels and biopsy findings. For image evaluation, each prostate was divided into 12 regions corresponding to the sites from which the 12 core biopsies were taken ( $\bullet$ Fig. 1 ) after consultation with the urologists who performed the biopsies. Each region was then assessed for the presence of prostate cancer using a 5-point scale ( 1 = definitely no tumor, 2 = probably no tumor, 3 = possibly tumor, 4 = probably tumor, 5 = definitely tumor) and the corresponding criteria are listed in Table $\mathbf{1}[5,11,12]$. To ensure their familiarity with the criteria, the three readers underwent brief training, in which datasets from patients not included in the study were used. 
Table $1 \quad 5$-point scoring scheme for prostate cancer on T2w images.

\begin{tabular}{|c|c|c|}
\hline & peripheral zone & transitional zone/central zone \\
\hline definitely benign tissue (1) & uniform hyperintense $t 2$ signal & $\begin{array}{l}\text { only BPH nodules, which were defined as round, well defined } \\
\text { lesions with a visible capsule and a mixed high and low signal } \\
\text { intensity on T2w images, because of their stromal and glandular } \\
\text { components }\end{array}$ \\
\hline probably benign tissue (2) & mild hypointensity with diffuse or feathered appearance & $\begin{array}{l}\text { nodules }>5 \mathrm{~mm} \text { with a visible capsule and with mixed high and low } \\
\text { signal intensity on } T 2 \mathrm{w}\end{array}$ \\
\hline possibly malignant tissue (3) & $\begin{array}{l}\text { ill-defined area of diffuse and inhomogeneous mild } \\
\text { hypointensity }\end{array}$ & area with homogeneous low T2 signal with preserved capsule \\
\hline probably malignant tissue (4) & mass-like appearance of mild hypointense area & area with homogeneous low T2 signal intensity without a capsule \\
\hline definitely malignant tissue (5) & $\begin{array}{l}\text { definite mass-like region of confluent moderate } \\
\text { hypointense area }\end{array}$ & $\begin{array}{l}\text { mass-like region of homogeneous low T2 signal intensity with len- } \\
\text { ticular shape, absence of a capsule and ill-defined margins (further } \\
\text { criteria: invasion of the anterior fibromuscular stroma) }\end{array}$ \\
\hline
\end{tabular}

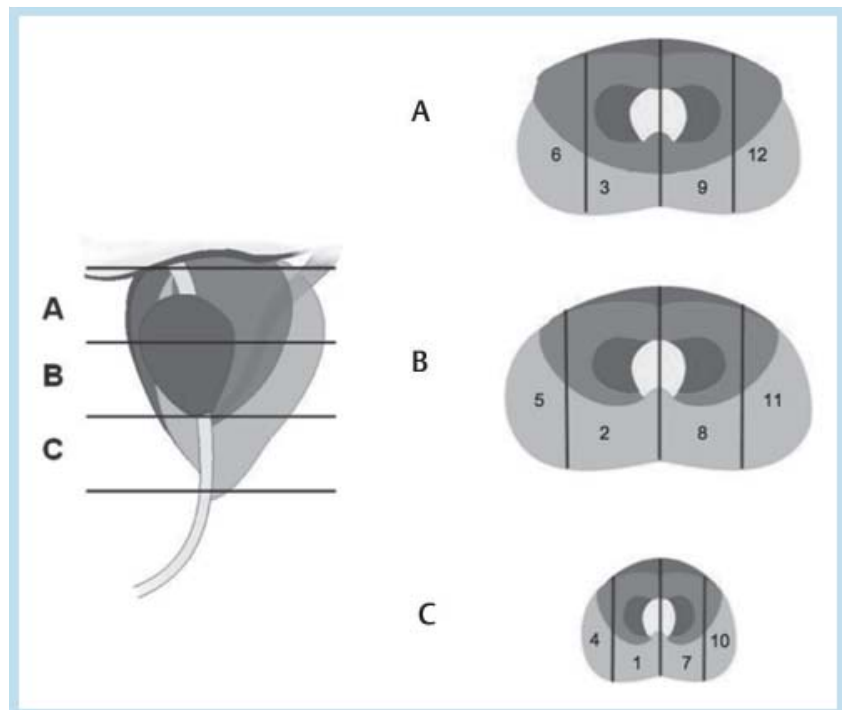

Fig. 1 Diagram showing the division of the prostate into 12 segments. Numbers give the order in which specimens are obtained in systematic TRUS-guided 12-core biopsy.

Abb. 1 Schemazeichnung zur Unterteilung der Prostata in 12 Areale. Die Ziffern entsprechen der Reihenfolge der systematischen TRUS-gestützten 12 fach-Biopsie.

\section{Statistical Tests}

Statistical analysis was performed for each reader on a per-region level. The patients were stratified based on the following groups: all cases, high-grade cancers, and low-grade cancers. Receiver operating characteristic (ROC) curves and the corresponding areas under the curves (AUCs) were estimated non-parametrically for the detection of cancer by each reader for each group. In all statistical methods, a p-value of less than 0.05 was considered to indicate a significant difference. The negative predictive value, sensitivity, specificity, and positive predictive value were calculated using dichotomized scores (benign tissue $=$ scores of 1 and 2; malignant tissue $=$ scores of 3,4 , and 5 ). The dichotomized scores were also used to calculate the Cohen's kappa coefficient for the interobserver agreement between the three readers, with $81-100 \%$ being classified as very good agreement, 61 $80 \%$ as good agreement, $41-60 \%$ as moderate agreement, 21 $40 \%$ as fair agreement, and $\leq 20 \%$ as poor agreement. Analyses were performed in MATLAB (version 7.1, Mathworks, Natick,
MA) and with commercially available statistical software (SPSS, 11.0; SPSS, Chicago, Ill).

\section{Results}

\section{Distribution of Prostate Cancer}

Among the 87 patients in the study, the median age was 66 years (range, 48 - 79 years) and the median PSA was $4.6 \mathrm{ng} / \mathrm{ml}$ (range, $1.7-34.2 \mathrm{ng} / \mathrm{ml}$ ). The median interval between MRI and biopsy was 19 days (range, 1 - 156 days). Systematic TRUS-guided 12core biopsy detected prostate cancer in $54 \%$ (47/87) of patients. In the patients with biopsy-proven prostate cancer, the median Gleason score was $3+3$ (range: $3+3$ to $4+5$ ) ( $\bullet$ Fig. 2 ). The median number of positive cores was 3 (range, $1-12$ ) ( $\bullet$ Fig. 3).

\section{Detection of All Prostate Cancers}

The 47 patients with positive biopsy results had a total of 184 positive cores. Accordingly, 860 biopsy cores were negative for prostate cancer. The three readers correctly identified 91 to 101 of the 184 cancer-positive regions, resulting in sensitivities of $49.5 \%$ (91/184) to $54.8 \%(101 / 184)$. Out of the 1044 regions biopsied, the three readers scored $705-776$ as negative on MRI, resulting in negative predictive values ranging from $87.4 \%(641 / 733)$ to $88.2 \%$ (622/705) ( $\bullet$ Fig. 4, $\odot$ Table 2 ). Of the 860 negative biopsy regions, they correctly identified 622 to 683 , resulting in specificities of $72.3 \%(622 / 860)$ to $79.4 \%(683 / 860)$. The positive predictive values ranged from $29.3 \%$ (92/311) to $34.0 \%$ (91/268). The AUCs for prostate cancer detection by MRI ranged from 0.65 to 0.67 (० Fig. 5, 6).

The Cohen's kappa coefficients for inter-reader agreement were fair to moderate ( 0.35 for reader 1 and reader 2, 0.45 for reader 1 and reader 3 , and 0.35 for reader 2 and reader 3 ).

\section{Detection of High-Grade Prostate Cancers}

Sensitivities ranged from $62.6 \%$ (67/107) to $69.2 \%$ (74/107) with negative predictive values ranging from $92.6 \%(499 / 539)$ to $93.1 \%$ (459/493) ( $\bullet$ Table 3 ). The AUCs for the detection of highgrade prostate cancer by MRI ranged from 0.75 to 0.76 ( $\odot$ Fig. 6 ). The Cohen's kappa coefficients indicated good inter-reader agreement at 0.65 for reader 1 and reader 2, 0.73 for reader 1 and reader 3 and 0.68 for reader 2 and reader 3 . 


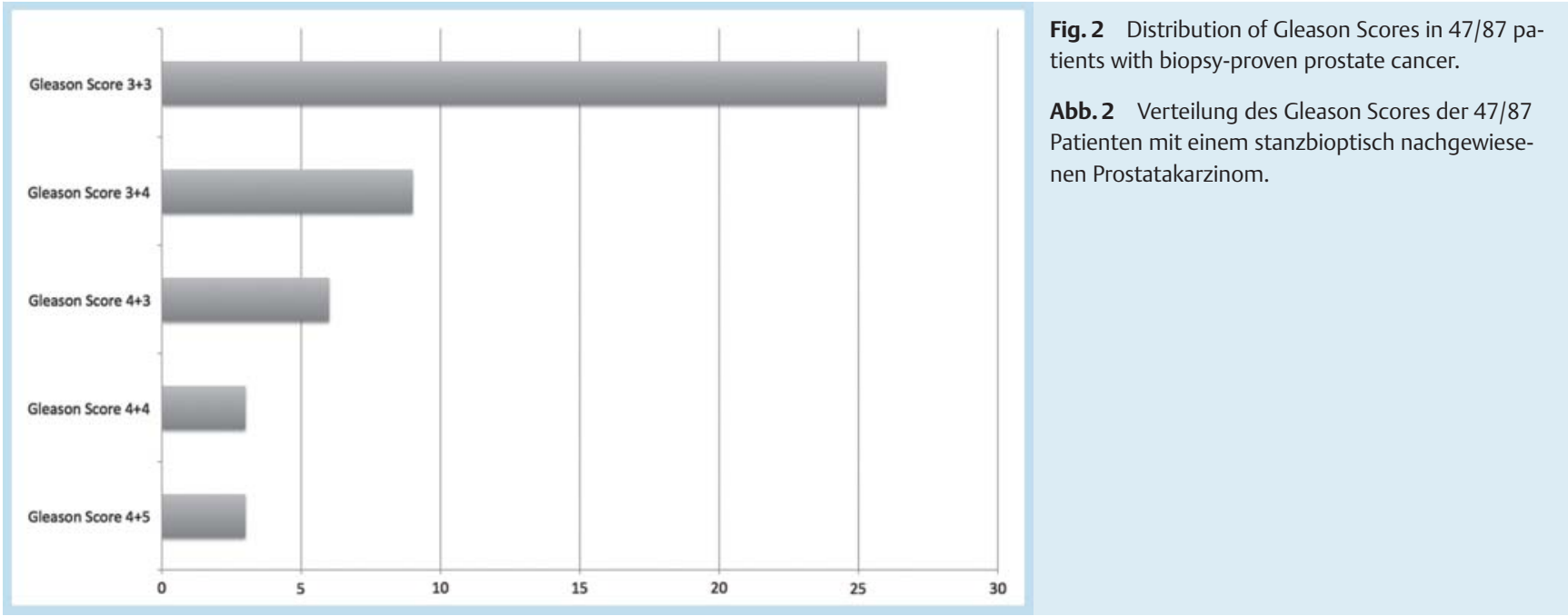

Table 2 Summary of sensitivity, specificity, negative and positive predictive value to detect all prostate cancers for scores dichotomized as benign $(1,2)$ vs. malignant $(3,4,5)$ for readers $1-3$ (level of reference: individual biopsy core).

\begin{tabular}{|lllll|} 
& sensitivity & specificity & negative predictive value & positive predictive value \\
\hline reader 1 & $49.5 \%(91 / 184)$ & $79.4 \%(683 / 860)$ & $88.0 \%(683 / 776)$ & $34.0 \%(91 / 268)$ \\
\hline reader 2 & $54.8 \%(101 / 184)$ & $72.3 \%(622 / 860)$ & $88.2 \%(622 / 705)$ & $29.8 \%(101 / 339)$ \\
\hline reader 3 & $50.0 \%(92 / 184)$ & $74.5 \%(641 / 860)$ & $87.4 \%(641 / 733)$ & $29.3 \%(92 / 311)$ \\
\hline
\end{tabular}

Table 3 Summary of sensitivity, specificity, negative and positive predictive value to detect high-grade prostate cancer for scores dichotomized as benign $(1,2)$ vs. malignant $(3,4,5)$ for readers $1-3$ (level of reference: individual biopsy core)

\begin{tabular}{|lllll|} 
& sensitivity & specificity & negative predictive value & positive predictive value \\
\hline reader 1 & $62.6 \%(67 / 107)$ & $79.8 \%(499 / 625)$ & $92.6 \%(499 / 539)$ & $34.7 \%(67 / 193)$ \\
\hline reader 2 & $69.2 \%(74 / 107)$ & $71.5 \%(447 / 625)$ & $93.1 \%(447 / 480)$ & $29.4 \%(74 / 252)$ \\
\hline reader 3 & $68.2 \%(73 / 107)$ & $73.4 \%(459 / 625)$ & $93.1 \%(459 / 493)$ & $30.5 \%(73 / 239)$ \\
\hline
\end{tabular}

Table 4 Summary of sensitivity, specificity, negative and positive predictive value to detect low-grade prostate cancer for scores dichotomized as benign (1,2) vs. malignant $(3,4,5)$ for readers 1 - 3 (level of reference: individual biopsy core).

\begin{tabular}{|lllll|} 
& sensitivity & specificity & negative predictive value & positive predictive value \\
\hline reader 1 & $31.2 \%(24 / 77)$ & $81.8 \%(585 / 715)$ & $91.7 \%(585 / 638)$ & $15.6 \%(24 / 154)$ \\
\hline reader 2 & $35.1 \%(27 / 77)$ & $76.4 \%(546 / 715)$ & $91.6 \%(546 / 596)$ & $13.8 \%(27 / 196)$ \\
\hline reader 3 & $24.7 \%(19 / 77)$ & $77.2 \%(552 / 715)$ & $90.5 \%(552 / 610)$ & $10.4 \%(19 / 182)$ \\
\hline
\end{tabular}

\section{Detection of Low-Grade Prostate Cancer}

For low-grade prostate cancer, the negative predictive values ranged from $90.5 \%(552 / 610)$ to $91.7 \%$ (585/638) and the sensitivities ranged from $24.7 \%(19 / 77)$ to $35.1 \%$ (27/77) ( $\bullet$ Fig. 7 , - Tab.4). The AUCs for the detection of low-grade prostate cancer by MRI ranged from 0.51 to 0.57 .

In the detection of low-grade prostate cancer, the Cohen's kappa coefficients for inter-reader agreement were fair $(0.26$ for reader 1 and reader 2, 0.31 for reader 1 and reader 3 and 0.26 for reader 2 and reader 3 ).

\section{Discussion}

$\nabla$

Our results show that if prostate cancer is not detected on a conventional endorectal prostate MRI examination performed before initial systematic TRUS-guided core biopsy, it is highly unlikely that the biopsy will detect cancer. The negative predictive value of MRI was highest for high-grade cancers, at $93 \%$ for each of the three readers.

There is a paucity of data in the literature regarding the use of newer multiparametric MRI techniques incorporating diffusionweighted imaging (DWI), dynamic contrast-enhanced MRI (DCEMRI), and/or ${ }^{1} \mathrm{H}$ MR spectroscopy $\left({ }^{1} \mathrm{H}-\mathrm{MRS}\right)$ before initial TRUSguided biopsy. One study with 155 patients showed that in patients with a PSA of $4-10 \mathrm{ng} / \mathrm{ml}$, the absence of malignant voxels on ${ }^{1} \mathrm{H}$-MRS was always associated with subsequent negative pros- 


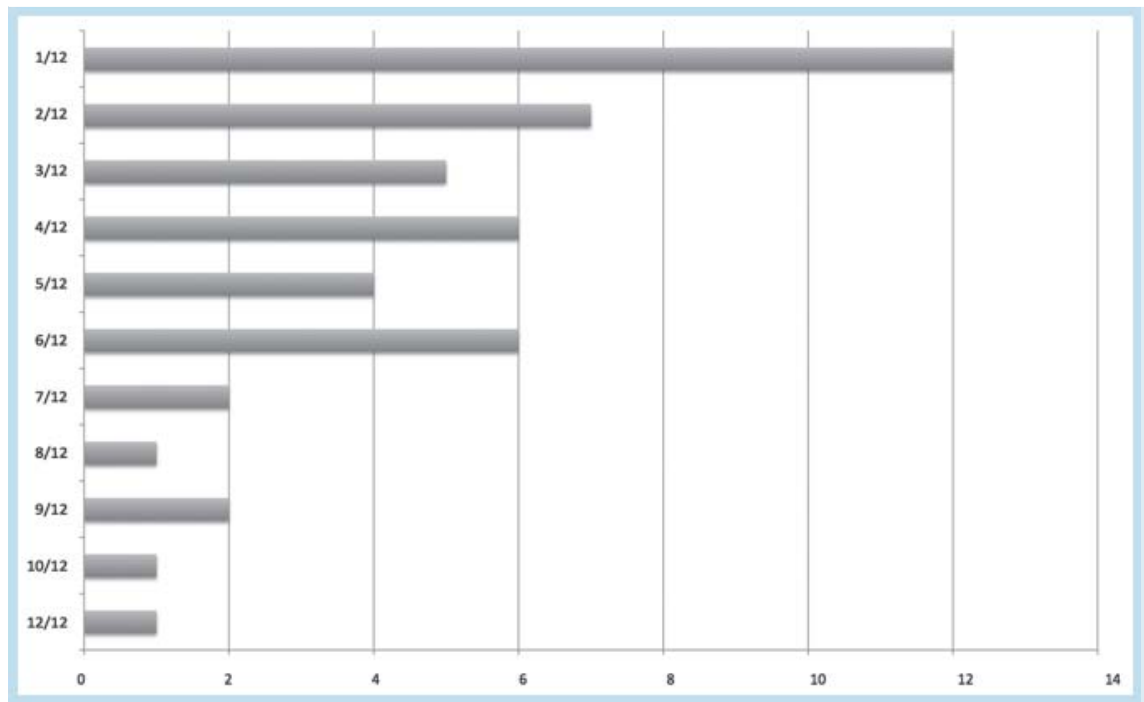

Fig. 3 Number of positive cores of 12 core systematic TRUS-guided biopsies in 47/87 patients with biopsy-proven cancer.

Abb. 3 Anzahl der positiven Stanzzylinder der systematischen TRUS gestützten 12 fach Biopsie bei den 47/87 Patienten mit einem stanzbioptisch nachgewiesenen Prostatakarzinom.
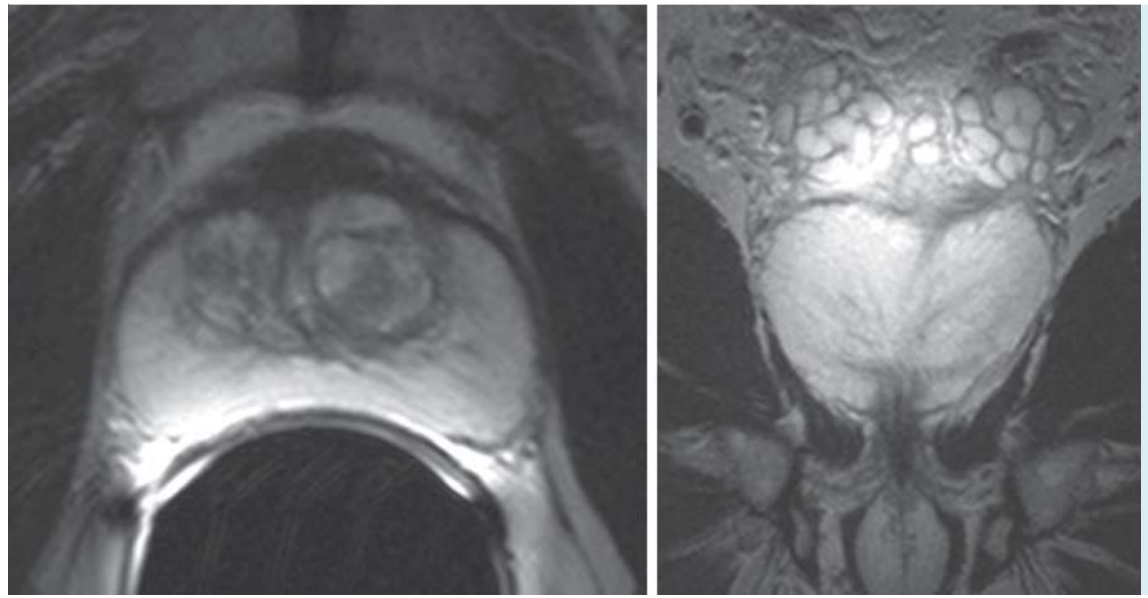

Fig. 4 Axial and coronal T2-weighted MR images (TR $3720 \mathrm{~ms}$, TE $100 \mathrm{~ms}$, ETL 13) of the prostate in a 67 -year-old man with a PSA of $3.42 \mathrm{ng} / \mathrm{mL}$. Histologically, all 12 cores were found to contain only normal prostate tissue. All three readers assigned scores of 1 or 2 to all 12 segments, classifying the whole gland as true negative.

Abb. 4 Axiale und coronare T2-gewichtete MRBilder (TR 3720 ms, TE 100 ms, ETL 13) einer Prostata eines 67 Jahre alten Mannes mit einem PSAWert von $3,42 \mathrm{ng} / \mathrm{ml}$. Histopathologisch fand sich in allen 12 Stanzzylindern der systematischen TRUSBiopsie normales Prostatagewebe. Alle drei Befunder bewerteten alle 12 Areale der Prostata auf der 5-Punkte-Skala mit 1 oder 2 und diagnostizierten die gesamte Prostata damit als richtig negativ.
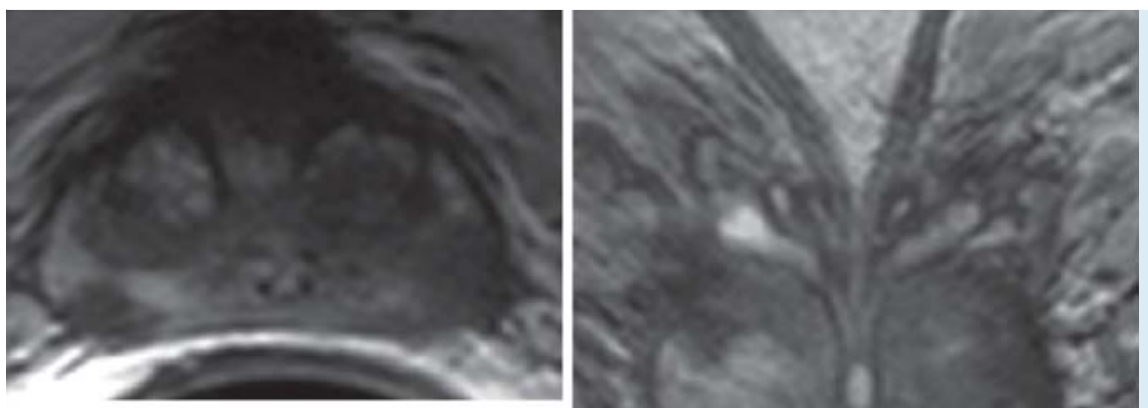

Fig. 5 Axial and coronal T2-weighted MR images (TR $3720 \mathrm{~ms}$, TE $100 \mathrm{~ms}$, ETL 13) of the prostate in a 71-year-old man with a PSA of $4.62 \mathrm{ng} / \mathrm{mL}$. Histologically, prostate cancer with a Gleason score of $4+3$ was diagnosed in the right base (specimens $3 \& 6$ ), in the left base (specimens $9 \& 12$ ), and in the left midgland (specimen 11). All three readers classified the right and left base and the left midgland as true positive (scores of 5 and 4 ).
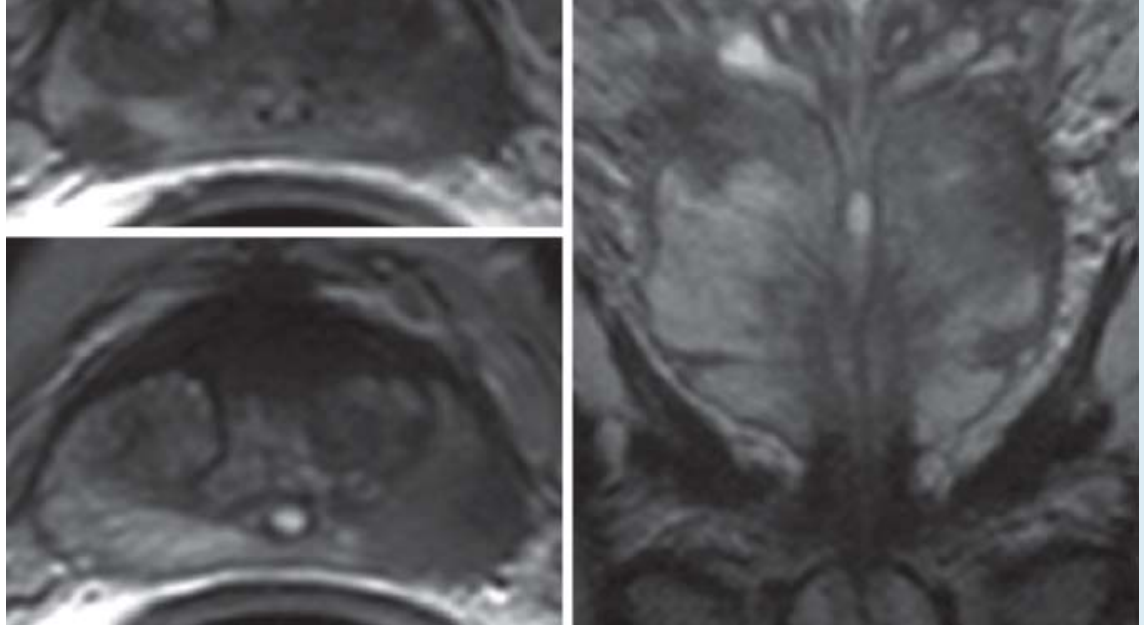

Abb.5 Axiale und koronare T2-gewichtete MRBilder (TR 3720 ms, TE 100 ms, ETL 13) einer Prostata eines 71 Jahre alten Mannes mit einem PSAWert von $4,62 \mathrm{ng} / \mathrm{ml}$. Histopathologisch wurde ein Prostatakarzinom mit einem Gleason Score von 4 + 3 rechts basal (Stanzbiopsie $3 \& 3$ ), links basal (Stanzbiopsie 9 \& 12) und in der mittleren Drüse links lateral (Stanzbiopsie 11). Alle drei Befunder bewerteten die Areale rechts basal, links basal und links lateral in der mittleren Drüse als richtig positiv (Punktwert 4 und 5).

tate biopsy results [6]. On the other hand plenty of studies have shown that patients with at least one negative TRUS-guided biopsy and a persistent clinical suspicion of prostate cancer benefit from
MRI $[5,16,17]$. Multiparametric MRI has been found to yield a greater negative predictive value than conventional endorectal prostate MRIin such patients and ranged from $78 \%$ to $95 \%$, with 

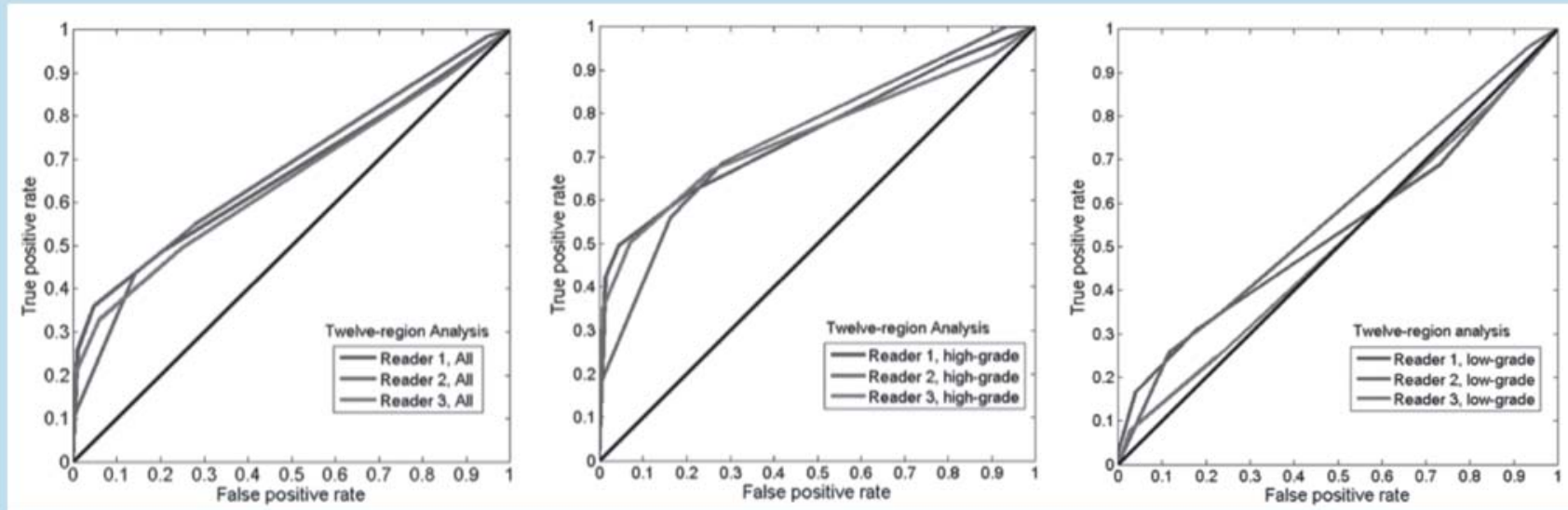

Fig. 6 Nonparametric receiver operating characteristic (ROC) curves with areas under the curve (AUC) for readers $1-3$ for all prostate cancers, high-grade cancers, and low-grade cancers.

Abb. 6 Nicht-parametrische receiver operating characteristic (ROC) curves mit den entsprechenden areas under the curve (AUC) der Reader 1 - 3 für highrisk-, low-risk- und alle Prostatakarzinome.
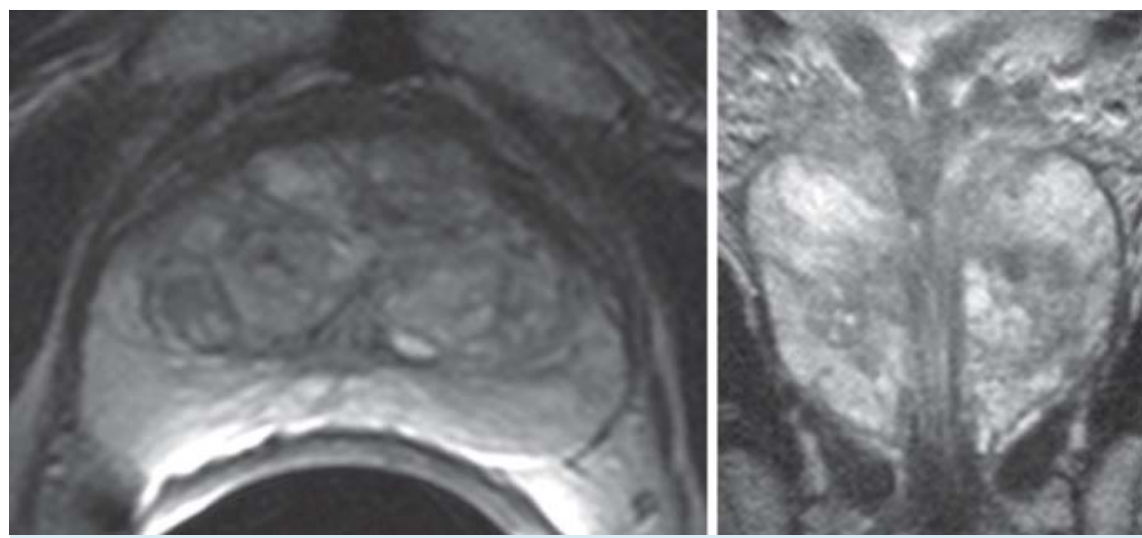

Fig. 7 Axial and coronal T2-weighted MR images (TR $3720 \mathrm{~ms}$, TE $100 \mathrm{~ms}$, ETL 13) of the prostate in a 79 -year-old man with a PSA of $4.26 \mathrm{ng} / \mathrm{mL}$. Histologically, prostate cancer with a Gleason score of $3+3$ was diagnosed in the right midgland (specimen 2). The other specimens contained no prostate cancer. All readers classified the right midgland falsely as negative (scores of 1 and 2). All other sites were correctly identified as benign (scores of 1 and 2 ). Only one reader incorrectly scored the left base as possibly malignant (score of 3 ) - image not shown.

Abb.7 Axiale und coronare T2-gewichtete MR Bilder (TR 3720 ms, TE 100 ms, ETL 13) einer Prostata eines 79 Jahre alten Mannes mit einem PSA Wert von $4,26 \mathrm{ng} / \mathrm{ml}$. Histopathologisch wurde ein Prostatakarzinom mit einem Gleason Score von $3+3$ in der mittleren Drüse rechts intermediär (Stanzbiopsie 2) nachgewiesen. Die anderen Stanzbiopsien enthielten kein Prostatakarzinom. Alle drei Befunder bewerteten das Areal in der mittleren Drüse rechts intermediär mit einem Punktwert von 1 oder 2 und damit falsch negativ. Alle anderen Areale wurden richtig negativ als benigne bewertet (Punktwert 1 und 2). Nur ein Befunder vergab für das Areal links basal einen Punktwert von 3 (Bild nicht abgebildet).

$[15,20,21]$. The application of pharmacokinetic models with different standardized or individualized arterial input functions, as well as the use of different DCE-MRI sequences with different temporal resolutions, has complicated the comparison of DCE-MRI results from different studies [15, 20, 21].

The sensitivities of conventional endorectal prostate MRI (which ranged from $49.5-54.8 \%$ for all cancers and $62.6-$ $69.2 \%$ for high-grade cancers) were lower than those in most published studies, although the specificities we found were similar to those previously reported. The published sensitivities for prostate cancer detection with conventional endorectal prostate MRI range from $74 \%$ to $81 \%$ [13, 14]. These higher sensitivities have been achieved in fundamentally different populations, namely patients who had histologically proven prostate cancer at the time of MRI and were scheduled for prostatectomy. In contrast, we investigated patients in whom prostate cancer was suspected based on an abnormal age-related PSA level, abnormal PSA velocity, or suspicious palpation findings. In a study of 40 pa-

highest numbers in studies using a diagnostic 5-point scale [16 18]. The diagnostic benefits of multiparametric MRI techniques are accompanied by some methodological limitations. ${ }^{1} \mathrm{H}-\mathrm{MRS}$ requires an acquisition time of at least $9 \mathrm{~min}$. and must be delayed until 6 - 8 weeks after the last prostate biopsy to prevent hemorrhage-related spectrally degraded voxels [19]. The apparent diffusion coefficient (ADC) calculated from DWI is a function of the signal-to-noise ratio and the applied b-values, which are functions of the diffusion gradients used [15]. As a result, it is difficult to compare ADC values obtained from DWI examinations performed on different scanners and with different $b$-values. For the analysis of DCE-MRI, several pharmacokinetic models and parameters exist tients without histologic proof of prostate cancer at the time of MRI, the sensitivity of conventional endorectal prostate MRI was also low, at $43 \%$, despite the fact that only the peripheral zone was analyzed and the hemiprostate was used as the unit of analysis for the results of core biopsy [8]. For the clinically important question whether the patient has prostate cancer or not, the corresponding patient-by-patient analysis lead to much higher sensitivities of $73 \%$ to $78 \%[7,9]$. The newer multiparametric MRI sequences will probably further improve the sensitivity, because already one study with patients with initial suspicion of prostate cancer and several studies with patients with continuous suspicion of prostate cancer after at least one negative biopsy 
showed a considerable improvement of sensitivity and diagnostic accuracy $[7,13,16,18]$.

We found good interobserver agreement for the detection of high-grade prostate cancers by MRI, suggesting that our results are reproducible in this clinical setting. The implementation of multiparametric MRI and structured, standardized reporting could further increase interobserver agreement [22]. It must be noted, however, that all three readers were experienced in interpreting conventional endorectal prostate MRI, and experience has been found to be crucial for the diagnostic accuracy of prostate MRI [23].

It is also important to note that in a study population such as the one investigated here, it is essential to ensure an efficient workflow with prompt reporting of results to referring physicians to minimize any delay in diagnosis that might negatively impact a patient's prognosis in the screening situation. A report providing information on suspicious MRI findings and their location(s) within the prostate allows the treating urologist to obtain biopsies without delay.

Our study is limited by the fact that we used systematic 12-core transrectal biopsy as the standard of reference. Twelve-core biopsy offers better cancer detection than sextant or octant biopsy, as used in earlier studies investigating the role of prostate MRI before initial biopsy, but in our opinion, it underestimates the extent of cancer, especially in apical and anterior portions of the prostate, resulting in an overestimation of the false-positive rate [24]. This dilemma might be overcome by extended follow-up of patients. In our study, extended follow-up was not possible because of the retrospective design and patients' increasing tendency to use different healthcare providers at different stages of disease. However, future studies should target longer patient follow-up. Alternatively, transperineal template mapping biopsies should be obtained, as they are the best gold standard in patients with suspected prostate cancer. Transperineal template mapping biopsy, using a line-by-line approach with sampling every $5 \mathrm{~mm}$ from the base to the apex of the gland, appears to be comparable in accuracy to pathological analysis of whole-mount prostatectomy specimens. While not detecting every micro-focus of cancer, transperineal template mapping biopsies identify $95 \%$ of all significant, life-threatening prostate cancers [25]. Another more practical approach would be targeted transrectal TRUS-guided biopsies of suspicious areas in addition to systematic 12-core transrectal biopsy.

In conclusion, our results suggest that conventional endorectal prostate MRI performed for suspected cancer before initial biopsy has a high negative predictive value, ruling out the detection of high-grade and low-grade cancers by subsequent TRUS-guided core biopsy with probabilities of $93 \%$ and $91 \%-92 \%$, respectively. Based on these data, in patients newly suspected of having prostate cancer who are reluctant to have a biopsy, MRI examination may provide useful information about the likelihood of cancer. However, the sensitivity of conventional endorectal prostate MRI in this subset of patients precludes the use of MRI alone in these patients and makes it necessary to closely monitor (e.g. by PSA testing) those who do not undergo prostate biopsy, regardless of their MRI findings. The sensitivity of conventional endorectal prostate MRI might be improved in the future by the supplementary use of newer techniques such as DWI, DCE-MRI, and ${ }^{1} \mathrm{H}-\mathrm{MRS}[9,26,27]$. Once adequate sensitivity can be achieved with MRI, MRI findings can be used to plan targeted biopsies, thus contributing to a marked reduction of core biopsies in the future.

\section{Acknowledgement}

$\nabla$

This manuscript is dedicated to Professor Bernd Hamm for his 60th birthday.

\section{References}

1 Djavan B, Milani S, Remzi M. Prostate biopsy: who, how and when. An update. Can J Urol 2005; 12: 44-48 discussion 99-100

2 Mkinen T, Auvinen A, Hakama M et al. Acceptability and complications of prostate biopsy in population-based PSA screening versus routine clinical practice: a prospective, controlled study. Urology 2002; 60: $846-850$

3 Vargas HA, Akin O, Franiel T et al. Diffusion-weighted endorectal MR imaging at $3 \mathrm{~T}$ for prostate cancer: tumor detection and assessment of aggressiveness. Radiology 2011; 259: 775 - 784

4 Mueller-Lisse U, Mueller-Lisse U, Scheidler J et al. Reproducibility of image interpretation in MRI of the prostate: application of the sextant framework by two different radiologists. Eur Radiol 2005; 15: 1826 1833

5 Beyersdorff D, Taupitz M, Winkelmann B et al. Patients with a history of elevated prostate-specific antigen levels and negative transrectal USguided quadrant or sextant biopsy results: value of MR imaging. Radiology 2002; 224: 701 - 706

6 Kumar R, Nayyar R, Kumar $V$ et al. Potential of magnetic resonance spectroscopic imaging in predicting absence of prostate cancer in men with serum prostate-specific antigen between 4 and $10 \mathrm{ng} / \mathrm{ml}$ : a follow-up study. Urology 2008; 72: 859-863

7 Tanimoto A, Nakashima J, Kohno H et al. Prostate cancer screening: the clinical value of diffusion-weighted imaging and dynamic MR imaging in combination with T2-weighted imaging. J Magn Reson Imaging 2007; 25: $146-152$

8 Costouros NG, Coakley FV, Westphalen AC et al. Diagnosis of prostate cancer in patients with an elevated prostate-specific antigen level: role of endorectal MRI and MR spectroscopic imaging. Am J Roentgenol Am J Roentgenol 2007; 188: 812 -816

9 Vilanova JC, Barcelo-Vidal C, Comet J et al. Usefulness of prebiopsy multifunctional and morphologic MRI combined with free-to-total prostate-specific antigen ratio in the detection of prostate cancer. Am J Roentgenol Am J Roentgenol 2011; 196: W715-W722

10 Gleason DF, Mellinger GT. Prediction of prognosis for prostatic adenocarcinoma by combined histological grading and clinical staging. J Urol 1974; 111: 58-64

11 Akin O, Sala E, Moskowitz CS et al. Transition zone prostate cancers: features, detection, localization, and staging at endorectal MR imaging. Radiology 2006; 239: 784-792

12 Haider MA, van der Kwast TH, Tanguay J et al. Combined T2-weighted and diffusion-weighted MRI for localization of prostate cancer. Am J Roentgenol Am J Roentgenol 2007; 189: 323 -328

13 Scheidler J, Hricak H, Vigneron DB et al. Prostate cancer: localization with three-dimensional proton MR spectroscopic imaging-clinicopathologic study. Radiology 1999; 213: 473 - 480

14 Lim HK, Kim JK, Kim KA et al. Prostate cancer: apparent diffusion coefficient map with T2-weighted images for detection-a multireader study. Radiology 2009; 250: 145-151

15 Franiel T. Multiparametrische Magnetresonanztomografie der Prostata - Technik und klinische Anwendungen. Fortschr Röntgenstr 2011; 183: $607-617$

16 Franiel T, Stephan C, Erbersdobler A et al. Areas suspicious for prostate cancer: MR-guided biopsy in patients with at least one transrectal USguided biopsy with a negative finding-multiparametric MR imaging for detection and biopsy planning. Radiology 2011; 259: 162-172

17 Sciarra A, Panebianco V, Ciccariello $M$ et al. Value of magnetic resonance spectroscopy imaging and dynamic contrast-enhanced imaging for detecting prostate cancer foci in men with prior negative biopsy. Clin Cancer Res 2010; 16: 1875-1883

18 Portalez D, Mozer P, Cornud F et al. Validation of the European Society of Urogenital Radiology scoring system for prostate cancer diagnosis on multiparametric magnetic resonance imaging in a cohort of repeat biopsy patients. Eur Urol 2012; 62: 986 - 996

19 Qayyum A, Coakley FV, Lu Y et al. Organ-confined prostate cancer: effect of prior transrectal biopsy on endorectal MRI and MR spectro- 
scopic imaging. Am J Roentgenol Am J Roentgenol 2004; 183: 10791083

20 Beyersdorff D, Lüdemann L, Dietz E et al. Dynamische kontrastmittelgestützte MRT der Prostata: Vergleich von zwei Auswerteverfahren. Fortschr Röntgenstr 2011; 183: 456-461

21 Franiel T, Hamm B, Hricak H. Dynamic contrast-enhanced magnetic resonance imaging and pharmacokinetic models in prostate cancer. Eur Radiol 2011; 21: 616-626

22 Quentin M, Arsov C, Rohlen S et al. Inter-reader agreement of multiparametric MR imaging for the detection of prostate cancer: evaluation of a scoring system. Fortschr Röntgenstr 2012; 184: 925-929

23 Scheidler J, Weores I, Brinkschmidt C et al. Diagnosis of prostate cancer in patients with persistently elevated PSA and tumor-negative biopsy in ambulatory care: performance of MR imaging in a multi-reader environment. Fortschr Röntgenstr 2012; 184: 130-135
24 Wefer AE, Hricak H, Vigneron DB et al. Sextant localization of prostate cancer: comparison of sextant biopsy, magnetic resonance imaging and magnetic resonance spectroscopic imaging with step section histology. J Urol 2000; 164: 400-404

25 Crawford ED, Wilson SS, Torkko KC et al. Clinical staging of prostate cancer: a computer-simulated study of transperineal prostate biopsy. BJU Int 2005; 96: 999-1004

26 Kumar V, Jagannathan NR, Kumar R et al. Apparent diffusion coefficient of the prostate in men prior to biopsy: determination of a cut-off value to predict malignancy of the peripheral zone. NMR Biomed 2007; 20: $505-511$

27 Kumar V, Jagannathan NR, Kumar R et al. Transrectal ultrasound-guided biopsy of prostate voxels identified as suspicious of malignancy on three-dimensional (1)H MR spectroscopic imaging in patients with abnormal digital rectal examination or raised prostate specific antigen level of 4-10 ng/ml. NMR Biomed 2007; 20: 11-20

Erratum „Franiel T et al. Role of Endorectal Prostate MRI in Patients with Initial Suspicion of Prostate Cancer. Fortschr Röntgenstr 2013; 185: $967-974^{\text {c6 }}$

In the above mentioned article the second author name was changed into H. A. Vargas. 